\section{Cláusulas abusivas en contratos de transporte aéreo de personas: doctrina jurisprudencial sobre el cargo por remisión de tarjeta de embarque}

\author{
Cristina Cano Ortega \\ Department of Law, Universidad de Almeria, Almeria, Spain
}

Transporte aéreo de personas

Received 19 March 2019 Revised 21 May 2019 Accepted 17 February 2020

\begin{abstract}
Purpose - Este artículo tiene por objeto analizar uno de los casos más importantes en los últimos años en los que se han declarado nulas ciertas cláusulas abusivas incluidas por las aerolíneas en los contratos de transporte aéreo con los consumidores, en concreto, se trata de la Sentencia de la Audiencia Provincial de Madrid, sección 28, de 26 de julio de 2017 y, especialmente, se estudiará la cláusula de cargo por remisión de la tarjeta de embarque.

Design/methodology/approach - A través del estudio de la mencionada sentencia, este trabajo mostrará cómo el contrato de transporte aéreo de personas siendo uno de los contratos más importantes actualmente, presenta una situación de especial desequilibrio y desprotección de los consumidores frente a las aerolíneas.

Findings - La falta de poder de negociación de los consumidores, las escasas alternativas que tienen en muchos casos y los precios generalmente altos de este contrato de transporte, hacen imprescindibles dispensar una protección adecuada a los consumidores en este contexto. Esto se puede lograr a través de leyes tuitivas que protejan sus intereses económicos y, especialmente como se analiza en el artículo, mediante la prohibición de cláusulas abusivas en los contratos de transporte aéreo.

Originality/value - El artículo hace un recorrido por algunas de las cláusulas abusivas incluidas en los contratos de transporte aéreo de pasajeros en los últimos años y muestra cómo debe evitarse que las aerolíneas impongan estas cláusulas que perjudican a la parte más débil del contrato y advierte que estamos aún lejos de conseguir una efectiva protección del consumidor en este ámbito como se explica con algún ejemplo final.
\end{abstract}

Keywords Cláusulas abusivas, Cláusula de cargo por reemisión de tarjeta de embarque, Transporte aéreo, Consumidores, Protección y condiciones generales de la contratación

Paper type Research paper

\section{Introducción}

El contrato de transporte se caracteriza por carecer de una regulación uniforme que depende del medio y objeto del transporte. En concreto, el transporte aéreo de personas es uno de los contratos de transporte más importantes actualmente al dar un gran impulso al turismo mundial. Es imprescindible dispensar una protección adecuada a los consumidores en estos contratos debido a la situación de especial desequilibrio en la que se encuentran frente a las aerolíneas, al carecer de

(C) Cristina Cano Ortega. Published in Journal of Tourism Analysis: Revista de Análisis Turístico. Published by Emerald Publishing Limited. This article is published under the Creative Commons Attribution (CC BY 4.0) license. Anyone may reproduce, distribute, translate and create derivative works of this article (for both commercial and non-commercial purposes), subject to full attribution to the original publication and authors. The full terms of this license may be seen at http:// creativecommons.org/licences/by/4.0/legalcode

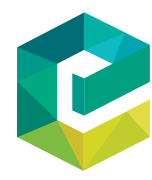

Journal of Tourism Analysis: Revista de Análisis Turístico Vol. 27 No. 2 , 2020 pp. $207-220$

Emerald Publishing Limited DOI 10.1108/JTA-03-2019-0014 
poder de negociación y al ser las alternativas escasas y los precios generalmente altos. Esto se puede lograr a través de leyes tuitivas que protejan sus intereses económicos y mediante la prohibición de cláusulas abusivas en los contratos de transporte aéreo. Sobre el papel de las Administraciones Públicas y la regulación del Turismo, puede verse Pérez (2014, 2017), Pérez and Ceballos (2009).

En nuestro régimen jurídico de los contratos rige el principio de la autonomía de la voluntad (art. $1255 \mathrm{CC}$ ), basado en el ideal de que ambas partes se encuentran en igualdad de condiciones para negociar. Sin embargo, por cuestión de economía de tiempo y de costes el uso de los contratos de adhesión se ha generalizado (García and Lastres, 2003, pp. 623-624). Así, dada la imposibilidad de que una compañía aérea negocie individualmente con cada pasajero las condiciones de su contrato de pasaje, la aerolínea redacta unilateralmente un contrato tipo que ofrece a los clientes para que si están interesados en el precio y condiciones del servicio contraten el vuelo con ella.

Aunque estos contratos sean redactados unilateralmente por una de las partes, y la capacidad de consentimiento de la otra parte se vea limitada, no impide apreciar su naturaleza contractual (O’Callaghan, 1994, p. 204). La problemática se encuentra en que al haber sido redactado por sólo una de las dos partes, el contrato tratará de favorecer a la parte predisponente. Debe evitarse que las aerolíneas impongan cláusulas abusivas a los consumidores.

En los siguientes apartados se analizará brevemente una de las sentencias más relevantes sobre cláusulas abusivas en el contrato de transporte aéreo de pasajeros, haciendo especial mención a una de las cláusulas que más debate suscitó en diferentes tribunales: el cobro por la reemisión de la tarjeta de embarque.

\section{El contrato de transporte aéreo de pasajeros}

El contrato de transporte aéreo de pasajeros es el acuerdo de voluntades por el que una aerolínea se compromete a trasladar de un lugar a otro por vía aérea mediante una aeronave al pasajero y a su equipaje, en el horario programado, a cambio del precio acordado (Zubiri, 2004, p. 1015). Este contrato se encuadra en los arrendamientos de obra (Petit and Guerrero, 2010, p. 342), ya que el transportista se compromete a alcanzar un determinado resultado: la realización del transporte para que el pasajero llegue a su destino.

Existen dos partes en este contrato que son el pasajero y el transportista, si bien podría haber algún intermediario como una agencia de viajes. El pasajero es la persona que es trasladada desde el punto de origen al destino por medio aéreo, siendo el transportista quien realiza dicha labor. Las obligaciones esenciales del pasajero son pagar el precio acordado, presentarse el día y hora establecidos (SAP de Palma de Mallorca, Sección $5^{\mathrm{a}}$, de 14 de junio de 2006) y respetar las normas de equipaje y seguridad; en cuanto a la del transportista es realizar el transporte de forma directa y profesional, llevando a su destino al pasajero.

En cuanto a la normativa aplicable, contamos con distintas normas dependiendo del ámbito del transporte (nacional o internacional y, en especial, comunitario), entre las que podemos mencionar la Ley 48/1960, de 21 de julio, sobre Navegación Aérea (LNA); el Reglamento (CE) $n^{\circ}$ 2027/97 del Consejo de 9 de octubre de 1997; el Reglamento (CE) $n^{\circ} 1008 /$ 2008 del Parlamento Europeo y del Consejo de 24 de septiembre de 2008; el Convenio para la unificación de ciertas reglas para el transporte aéreo internacional de 28 de mayo de 1999 (Convenio de Montreal); etc., incluso el Reglamento (CE) $n^{\circ}$ 593/2008 del Parlamento Europeo y del Consejo de 17 de junio de 2008 (Roma I).

\section{La protección de los consumidores frente a las cláusulas abusivas}

La protección de los consumidores tiene el carácter de principio informador en nuestro ordenamiento (art. $51 \mathrm{CE}$ ) y encuentra su fundamento en la desigualdad existente entre las partes 
contratantes causada por la mayor competencia y pericia del empresario (Botana, 2011, p. 1073). No se trata de proteger a personas débiles o inexpertas, sino de proteger el consumo como función económica y de la protección de la competencia (Miquel, 2011, p. 716).

El legislador español y el comunitario han querido proteger al consumidor frente a los posibles abusos que puedan sufrir por parte de los profesionales que hayan incorporado cláusulas generales que, "en contra de las exigencias de la buena fe causen, en perjuicio del consumidor y usuario, un desequilibrio importante de los derechos y obligaciones de las partes que se deriven del contrato" (art. 82.1 del Real Decreto Legislativo 1/2007, de 16 de noviembre, por el que se aprueba el texto refundido de la Ley General para la Defensa de los Consumidores y Usuarios y otras leyes complementarias -TRLGDCU-). Las cláusulas no negociadas individualmente deben cumplir ciertos requisitos para ser incorporadas a los contratos: concreción, claridad, sencillez en la redacción, accesibilidad y legibilidad, buena fe y justo equilibrio entre los derechos y obligaciones de las partes (art. 80 TRLGDCU). Esta protección la podemos encontrar a nivel comunitario en la Directiva 2011/83/UE del Parlamento Europeo y del Consejo de 25 de octubre de 2011.

En cuanto al comercio electrónico, este aporta numerosas ventajas al consumidor, ya que amplía su capacidad de acceso a cualquier producto, le permite comparar ofertas, reduce los intermediarios, etc. (Fernández, 2002, p. 250). En los casos de contratación electrónica del transporte aéreo de pasajeros debe tenerse en cuenta asimismo la normativa sobre la venta a distancia.

Aunque se tratara de un contrato electrónico, si las cláusulas han sido incorporadas al contrato por una de las partes en el marco de su actividad y para incorporarlas a una pluralidad de contratos serán "condiciones generales de la contratación” (Clemente, 2002, p. 366). Además, en algunos supuestos, en los contratos de transporte internacional, los artículos 82 a 91 del TRLGDCU también pueden ser aplicables, pues el legislador ha previsto unas normas de extensión recogidas en el artículo 67 TRLGDCU para que también se aplique en los supuestos de contratos "internacionales" (Castellanos, 2011, pp. 592-593).

Sobre cláusulas abusivas en estos contratos pueden verse sentencias como la de la AP de Madrid (Sección 28 ), de 17 de julio de 2015, en la que se confirma la sentencia de primera instancia en la que la "Organización de Consumidores y Usuarios" (OCU) ejercitaba acción colectiva pidiendo la declaración de nulidad de determinadas cláusulas generales de la contratación de IBERIA, y cuyo recurso de casación ante el TS ha sido admitido (Auto de 13 de junio de 2018 de la Sala de lo Civil, Sección $1^{\text {a }}$ del TS). Además, también ha sido un tema tratado por la doctrina (Pazos, 2018; Otero, 2017; Martín, 2013; Martínez, 2013; Vázquez, 2015).

\section{La sentencia de la audiencia provincial de Madrid de 26 de julio de 2017}

La OCU ejerciendo la acción de cesación contemplada en el artículo 12.2 Ley 7/1998, de 13 de abril, sobre condiciones generales de la contratación (LCGC), presentó demanda contra Ryanair Limited suplicando que se dictase sentencia declarando abusivas determinadas cláusulas de los "Términos generales y condiciones de Transporte" publicados en su página web. Dicha demanda fue estimada parcialmente por el Juzgado de lo Mercantil $n^{\circ} 5$ de Madrid con fecha 30 de septiembre de 2013. Contra dicha sentencia se presentaron sendos recursos de apelación interpuestos por Ryanair y la OCU, resueltos en la SAP de Madrid, sección 28, núm. 392/2017, de 26 de julio de 2017.

La abusividad de las cláusulas se examinó en primera instancia conforme al TRLGDCU, sin embargo, en la SAP se evalúa a la luz del derecho irlandés, siguiendo las pautas establecidas por el TJUE al interpretar las disposiciones de la Directiva 93/13, apreciadas en función de las circunstancias del caso. Esto se debe a que el TJUE ha establecido que la ley aplicable a la apreciación de una cláusula contractual debe determinarse siempre con arreglo al Reglamento
Transporte aéreo de personas 
Roma I (STJUE de 28 de julio de 2016, C-191/15, Verein für Konsumenteninformation). El Reglamento Roma I excluye expresamente los contratos de transporte de pasajeros distintos de los relativos a un viaje combinado del régimen establecido para los contratos de consumo. Así, según el artículo 5.2 del Reglamento Roma I, el primer criterio para la determinación de la ley aplicable es la autonomía de las partes, si bien la libertad de elección queda limitada a alguna de las leyes nacionales que el propio precepto señala. Entre ellas figura la del país donde el transportista tenga el lugar de su administración central, por lo que los "Términos generales y condiciones de Transporte" establecidos para los contratos celebrados por Ryanair con sus pasajeros, con ciertas salvedades, se regirán por la legislación de Irlanda por ser el país en el que la aerolínea tiene su administración central.

(1) La AP, estimando parcialmente el recurso de ryanair, revoca y deja sin efecto la sentencia anterior en cuanto a la declaración de nulidad de determinadas cláusulas

- La cláusula de elección de ley aplicable contenida en el primer inciso del artículo 2.4. Ley aplicable y jurisdicción: "Salvo por disposición en contrario del Convenio o la legislación aplicable, el contrato de transporte con nosotros, los Términos y Condiciones de Transporte y nuestros Reglamentos se regirán e interpretarán de conformidad con la legislación de Irlanda. Cualquier disputa que surja de o en conexión con este contrato estará sujeta a la jurisdicción de los tribunales irlandeses".

La AP de Madrid mantiene la abusividad de la cláusula de elección de foro por falta de transparencia al considerar que puede inducir a error al pasajero, ejerciendo como elemento disuasorio para él, al darle la impresión de que si quiere ejercitar contra Ryanair una acción indemnizatoria amparada en el Convenio de Montreal debería hacerlo necesariamente ante un tribunal irlandés. Ello provocaría un desequilibrio importante entre los derechos y obligaciones de las partes.

En cambio, en cuanto a la cláusula de elección de ley aplicable, considera la AP que el pasajero no puede verse privado del nivel mínimo de protección que le otorgan las normas de competencia internacional recogidas en el Convenio de Montreal, que tienen carácter imperativo. Aunque las cláusulas de Ryanair no lo digan expresamente, el pasajero que quiera ejercitar una acción de indemnización de daños contra la aerolínea con base en el régimen del Convenio de Montreal podría hacerlo, por lo que no considera nula la cláusula en ese aspecto.

- Los artículos 8.3.2 y 8.3.3. Equipaje. Objetos no aceptables como equipaje. Derecho a denegar el Transporte. 8.3.2. "No puede incluir dentro del equipaje facturado dinero, joyas, metales preciosos, llaves, cámaras, ordenadores, medicamentos, gafas, gafas del sol, lentes de contacto, relojes, teléfonos móviles, cigarrillos, tabaco o productos del tabaco, u otros objetos de valor, documentos comerciales, pasaportes y otros documentos de identificación o muestras". 8.3.3. "Si a pesar de resultar prohibido su transporte, cualquiera de los objetos mencionados en este Artículo 8.3 figura incluido en su equipaje, no seremos responsables de ninguna pérdida o daño producidos en estos objetos".

La AP revoca la previa declaración de nulidad realizada por la sentencia dictada en primera instancia de dicha cláusula. Para ello se basa en el régimen de responsabilidad del transportista por los daños ocasionados al equipaje que el establece el Convenio de Montreal que es más severo para el caso del daño sufrido por el equipaje facturado ya que la aerolínea garantiza su tratamiento y custodia. Como ello puede suponer ciertos costes adicionales para el transportista aéreo, entiende la AP que el transportista a la hora de fijar el precio que debe pagarse por el transporte y las condiciones en que se aplica 
dicho precio, pueda establecer que para evitar los eventuales costes de responsabilidad anteriormente citados, esos productos más frágiles y caros no se puedan llevar en el equipaje facturado, pero sí en el equipaje de mano de cuya custodia en principio se encarga el propio pasajero.

(2) Por otra parte, también estima la AP de Madrid parte del recurso interpuesto por la OCU Para que sean consideradas nulas ciertas cláusulas. En concreto, la SAP declara nulos

- El artículo 4.2.2. Precios, tasas, impuestos y cargos: "Las tasas, los impuestos y los cargos que se aplican al transporte aéreo cambian constantemente y puede ser que se impongan después de la fecha en la que se realizó su reserva. Si se impone o se aumenta una tasa, impuesto o cargo después de que haya hecho la reserva, estará obligado a pagarlo (o pagar el aumento) antes de la salida. Del mismo modo, si una tasa, impuesto o carga se anula o se reduce, y ya no se le aplica, o el importe consiguiente que debe pagar es inferior, tiene derecho a exigirnos que le reembolsemos la diferencia".

La AP la considera abusiva en virtud del artículo 85.10 TRLGDCU pues se obliga al usuario a mantener el contrato sin derecho a resolverlo si el precio final que resulta de la repercusión de la nueva tasa, impuesto o cargo o el aumento de alguno de ellos que integraban el precio en el momento de efectuar la reserva es muy superior al inicialmente previsto en el contrato.

- El párrafo incluido en el subapartado "Pasajeros invidentes o con discapacidad visual" dentro del apartado "Pasajeros con movilidad reducida, invidentes o con deficiencias visuales, condiciones medias o pasajeros que requieran una asistencia especial en el aeropuerto" de los Reglamentos de Ryanair sobre materias específicas que figuran como anexo que establece que "Los perros guía/de asistencia que acompañan pasajeros se transportan en las rutas aprobadas de forma gratuita, siempre y cuando los perros sean compatibles con el Plan de Mascotas de Viaje (pulse aquí para acceder al enlace)”.

Considera la AP que la remisión a una página web ajena redactada en inglés supone un motivo suficiente para considerar que no concurren los requisitos exigidos por el artículo 5 de la Directiva 93/13 y los artículos 5.5 LCGC y 80.1 TRLGDCU para ser una cláusula válida..

- $\quad$ El artículo 7.1.2.4. Denegación del Transporte: "Además nos podemos negar a transportarles o transportar su Equipaje si se produce una o más de las siguientes situaciones, o si creemos que se puede producir: (...) 7.1.2.4. Si ha mostrado una mala conducta en un vuelo anterior y tenemos motivos para creer que esta conducta podría repetirse".

La AP considera que la cláusula es ambigua y que está vinculada a la apreciación subjetiva del transportista, sin que quepa asociar esa "mala conducta" a un comportamiento amenazante para la seguridad del avión, que es lo que sí toma el PNS (Plan Nacional de Seguridad) como referente al hablar de "pasajero conflictivo". La cláusula es considerada nula por esa indeterminación y ambigüedad que deja en manos de la interpretación subjetiva del transportista la denegación del transporte si considera que concurre el supuesto.

- $\quad$ El artículo 8.5.1 y 8.5.2. Derecho de registro: 8.5.1. "Por motivos de seguridad, podemos requerir que nos permita registrarle e inspeccionarle por escáner, y de registrar, inspeccionar por escáner o rayos X su Equipaje. Podemos registrar su Equipaje aunque no se encuentre presente, con el objeto principal de determinar 
JTA

27,2

\section{2}

si se encuentra en posesión de o si su Equipaje contiene cualquiera de los objetos descritos por el Artículo 8.3. anterior o el Artículo 10.8 siguiente. 8.5.2. $\mathrm{Si}$ no atiende este requerimiento, podemos negarnos a transportarle $\mathrm{y}$ transportar su Equipaje. En caso de que un registro o una inspección por escáner le causara daños, o que un registro o una inspección por escáner o rayos X causara daños a su Equipaje no seremos responsables, salvo que la causa sea debida a culpa o negligencia por nuestra parte".

Como afirma la AP de Madrid la cláusula debe ser considerada abusiva ya que las únicas personas autorizadas para llevar a cabo la actuación prevista en las cláusulas mencionadas, en la medida en que supone una invasión en el ámbito de privacidad del sujeto, son quienes legalmente están facultados para ello, y Ryanair como entidad privada con la que se celebra un contrato no puede tener tal consideración. La cláusula es nula según el artículo 86.7 TRLGDCU. Igualmente también es nula la cláusula 8.5.2 al alterar el régimen de responsabilidad del transportista por daños en el equipaje previsto en el artículo 17.2 del Convenio de Montreal siendo subsumible en los supuestos del artículo 86.1 y 86.2 TRLGDCU.

(3) Por otra parte, se mantiene la declaración de nulidad realizada en primera instancia de las siguientes cláusulas

- La cláusula del artículo 3.1.1 Reservas y Documentación. Disposiciones generales y Anexo: "Prestamos servicio de transporte únicamente a1/los Pasajero/s el nombre cuyo/s nombre/s figura/n en la Confirmación/Itinerario. Le pediremos que pruebe su identidad y que cumpla con nuestros Reglamentos relativos a la documentación". "Reglamentos de Ryanair sobre materias específicas" "Anexos". "Las tarjetas de residencia, el permiso de conducir, los libros de familia, las libretas de identificación marítima, un informe de la policía (expedida en caso de pérdida del documento de viaje o robo), tarjetas de identificación militares, entre otros, $\mathrm{NO}$ se aceptarán como documentos válidos. Las identificaciones con fotografía caducadas o dañadas no se aceptarán en ningún vuelo".

La AP confirma la declaración de nulidad del mencionado artículo al considerar que el artículo 9 del Reglamento Roma I supone una excepción al principio de libre elección de la ley aplicable por las partes del contrato previsto en el artículo 3.1, y en el artículo 5.2 específicamente para el contrato de transporte de pasajeros. Así el artículo 9.2 dispone que las disposiciones del mismo no restringirán la aplicación de las leyes de policía de la ley del foro, por lo que en este aspecto la ley española desplazaría a la aplicación de la legislación irlandesa (en este sentido, art. 8.1 CC y art. $7^{\circ} \mathrm{LNA}$ ).

El artículo 10 del Reglamento 300/2008 establece que "todos los Estados Miembros habrán de elaborar, aplicar y mantener un programa nacional de seguridad para la aviación civil”, el cual "determinará responsabilidad para la aplicación de las normas básicas contempladas en el artículo 4 y describirá las medidas exigidas a los operadores y entidades a tal fin”. Y del artículo 13.3 del mismo Reglamento se deduce que si el programa de seguridad de una compañía aérea comunitaria ha sido validado por la autoridad competente del Estado miembro que haya concedido la licencia de explotación, no quita que los demás Estados miembros puedan exigir la observancia de especificidades del programa nacional de seguridad para la aviación civil de otro Estado miembro en el que preste sus servicios. 
Como consecuencia, no se trata de que Ryanair tenga que elaborar y aplicar un programa de seguridad para cada uno de los Estados miembros en los que preste sus servicios, sino que los Estados miembros distintos de Irlanda en que opere, pueden exigirle que aplique sus programas nacionales para la seguridad de la aviación civil cuando opera en ellos. En nuestro caso, debe respetarse el PNS (Programa Nacional de Seguridad para la Aviación Civil).

- Cargo de 40 euros del Anexo Tabla de Cargos contenida en el anexo de las condiciones generales de la contratación. Analizaremos con mayor detalle la nulidad de esta cláusula en el siguiente epígrafe.

- Cláusula 7.1.1. Denegación del transporte: "Nos podemos negar a transportarles o transportar su equipaje, siempre y cuando os hayamos remitidos una notificación de nuestra intención de no transportarles en ninguno de nuestros vuelos en ningún momento a partir de la fecha de dicha notificación".

La sentencia impugnada afirmaba que la cláusula no cumplía las exigencias del artículo 5 LCGC, porque podría suponer que RYANAIR pudiera denegar a voluntad el transporte tras la celebración del contrato. En cambio, la aerolínea sostenía que tal facultad es inherente a la libertad de contratación de la que goza la empresa y no puede ser catalogada como abusiva. La AP, si bien reconoce la libertad del transportista para celebrar contratos como afirma el artículo 27 del Convenio de Montreal, considera que en el ámbito de los contratos con consumidores dicha afirmación debe modularse, pues cuando se trata de bienes o servicios esenciales o de primera necesidad o con una oferta limitada o en otros supuestos en los que el consumidor se ve obligado a contratar con el empresario (como sería en el caso del transporte aéreo, de destinos exclusivos o de rutas directas), tal cláusula con tanta amplitud en su redacción, podría suponer una eventual negativa a contratar en tales casos.

- El artículo 8.8.1. Equipaje. Recogida y entrega de equipaje facturado: "De acuerdo con el artículo 8.6.3, se le exige que recoja el equipaje facturado tan pronto como este se ponga a su disposición en el destino. Si no lo recoge en un periodo de tiempo razonable, le podemos cobrar un cargo en concepto de almacenamiento. Si no reclama su equipaje facturado en los tres (3) meses siguientes desde el momento en que se puso a su disposición, podremos deshacernos de él sin incurrir por ello en ninguna responsabilidad hacia usted".

Dicha cláusula no remite a ninguna tabla de cargos como sí sucede en otros supuestos, por lo que no hace posible conocer cuándo se incurrirá en un recargo por la no recogida del equipaje ni qué recargo se aplicará por tal concepto. Esto supone que la cláusula no cumpla con el requisito de concreción que imponen los artículos 5.5 LCGC y 80.1.a) TRLGDCU, dando al empresario la facultad de integrar el contenido del contrato según su propia interpretación. Por ello, la AP confirma la declaración de nulidad de dicha cláusula.

- Artículo 9.1. Horarios, cancelaciones, retrasos y desvíos. Horarios. 9.1.1. "Los horarios de vuelos indicados en su confirmación/itinerario o en cualquier otro lugar pueden variar entre la fecha de la reserva y la fecha del viaje". 9.1.2. "En el momento de aceptar su reserva, le notificaremos el horario de vuelo programado en ese momento y este estará indicado en su confirmación/ itinerario. Es posible que necesitemos cambiar el horario de vuelo previsto después de que haya realizado la reserva. Si nos proporciona su dirección 
JTA

27,2

\section{4}

electrónica y un teléfono de contacto, intentaremos notificarle estos cambios por dicho medio. En las situaciones no contempladas en el artículo 9.2 siguiente, si después de efectuar su reserva pero antes de la fecha del viaje hay un cambio en la hora de salida prevista superior a tres horas y ellos le es inaceptable y no podemos procurarle una reserva en un vuelo alternativo que le sea aceptable, tendrá derecho al reembolso de todas las cantidades pagadas con relación al vuelo cambiado de horario, sin ninguna otra responsabilidad".

La SAP confirma la declaración de nulidad de dicha cláusula pues, a pesar de que la cláusula prevé un derecho de reembolso a favor del pasajero, no quita que reconoce a Ryanair la posibilidad de poder cambiar el horario de vuelo si lo necesita, sin ni siquiera tener que alegar ciertas razones para tal cambio. Por tanto, dicha cláusula debe considerarse abusiva en virtud de la Directiva 93/ $13 \mathrm{y}$ el artículo 85.3 TRLGDCU al no especificar los motivos por lo que se pudieran entender justificados los cambios del horario de vuelo impuestos al pasajero, tratándose de un elemento esencial del contrato.

- Artículo 18. Transacciones en efectivo o con tarjeta de crédito/débito. "Vistos los elevados costes administrativos y de seguridad, Ryanair no acepta dinero en efectivo para abonar tarifas aéreas, tasas o cargos por el transporte del exceso de equipaje y material deportivo. Algunos aeropuertos disponen de organización local para la aceptación de dinero en efectivo y a menudo aceptan las principales tarjetas de débito expedidas en sus países. Los pasajeros que quieran pagar por estos conceptos en el aeropuerto deben ponerse previamente en contacto con este para saber si acepta pagos en efectivo y/o qué tarjetas de débito acepta como forma de pago. A los pasajeros que abonen sus vuelos con tarjeta de crédito en una divisa diferente a la divisa del país desde donde sale el vuelo, el importe se les cargará en la divisa del país donde se ha expedido la tarjeta de crédito, también en caso de un cargo de un "usuario extranjero" pero puede comprobar el importe real que se cargará en la divisa de su tarjeta antes de que se efectúe el pago".

Del artículo 1170 CC se deduce que dentro de la unidad monetaria del sistema monetario nacional, las monedas y billetes son mera expresión física de la moneda de curso legal, y según el Banco de España, el reconocimiento a una moneda de curso legal supone que el pago de cualquier deuda no puede ser rechazado cuando se realiza con las expresión física de la misma, por lo que nadie puede oponerse al pago en efectivo, salvo por causas especiales de orden público que puedan limitar o condicionar dicha regla. Por ello, la AP mantiene la nulidad de esta cláusula.

\section{La cláusula de cargo por reemisión de tarjeta de embarque}

5.1 La obligación de emisión del billete electrónico y tarjeta de embarque

La mayor parte de la doctrina (Broseta and Martínez, 2018; Fernández, 2001), interpretando el artículo 3 del Convenio de Montreal, sostiene que el porteador está obligado a expedir y entregar el billete al viajero. La emisión del billete no es un requisito esencial para la existencia del contrato o la validez del mismo (Zubiri, 2004), y la exigencia de la emisión del mismo impuesto al transportista no convierte al contrato en un contrato formal (SánchezCalero and Sánchez-Calero, 2011).

Entre las funciones que desempeña el billete destaca la probatoria de la existencia del contrato y de que el pasajero ha realizado el pago, además de otorgar legitimidad a la persona que lo posee (Sentencia del Juzgado de lo Mercantil núm. 1 de Málaga de 1 septiembre de 2006), y permitir al porteador seguir las normas de seguridad establecidas. 
Actualmente, la emisión electrónica del billete la llevan a cabo todas las compañías aéreas. La ventaja que aporta el billete electrónico son costes reducidos, menor gestión, mayor comodidad y menores márgenes de error (López Bonilla and López Bonilla, 2008).

La tarjeta de embarque no aparece expresamente mencionada en la normativa. Es un documento que incorpora las condiciones del vuelo, el nombre del pasajero, de la compañía, el número de vuelo, la hora de embarque, el asiento asignado, etc., y la emiten las compañías aéreas cuando se produce el registro del pasajero (check in) (Guerrero, 2003). La necesidad de este documento se debe a la imposición del artículo 29.f) del Convenio de Chicago de 1944 sobre aviación civil internacional que requiere que en los vuelos de pasaje la aeronave lleve una lista de los pasajeros embarcados con sus lugares de origen y destino, pues no todos los que obtienen el billete definitivamente realizan el embarque. Aunque no establece expresamente a quién corresponde cumplir la obligación de confeccionar la lista de pasajeros, debe entenderse que recae sobre el transportista, puesto es quien puede conocer los pasajeros que han realizado el check in y volarán finalmente en la aeronave. Como consecuencia debe ser él mismo el obligado a expedir la tarjeta de embarque para cada pasajero como sucede con el billete.

\subsection{Las sentencias españolas sobre la cláusula que exige al pasajero la impresión de la tarjeta de embarque}

5.2.1 Acción individual. En la sentencia del Juzgado de lo Mercantil núm. 1 de Barcelona de 10 de enero de 2010, el Tribunal se pronunció sobre la demanda interpuesta por un usuario que había contratado con la compañía Ryanair un billete de transporte aéreo de ida y vuelta. Presentado en el aeropuerto el día del inicio del viaje, la compañía aérea le cobró 40 euros de penalización por no llevar impresa la tarjeta de embarque, por lo que el pasajero pedía al Tribunal la devolución de este dinero al considerar dicha cláusula abusiva (sobre este asunto, Cano Ortega, 2013; o sobre otros conflictos con la aerolínea Gómez Lozano, 2010; y en cuanto a jurisprudencia: por denegación de embarque por ejemplo la Sentencia de lo Mercantil núm. 9 de Barcelona, de 17 de marzo de 2011; o la SAP de Valencia, Sección $9^{\text {a }}$, de 9 de marzo de 2009). La aerolínea se defendía sosteniendo que cumple con su obligación al remitir al pasajero la tarjeta de embarque vía electrónica en formato PDF. Además, argumentaba que se trata de una empresa "low cost" que necesita adoptar este tipo de políticas para poder ofrecer a los viajeros bajos precios en sus billetes, condiciones de las que el viajero es informado y que libremente acepta.

La cláusula discutida está contemplada en el artículo 6 de los Términos Generales y Condiciones de Transporte de Ryanair (que ha ido sufriendo algunas modificaciones) que prevé que para aquellos casos en los que no pueda presentarse una Tarjeta de Embarque válida en los puntos de seguridad del aeropuerto o en la puerta de embarque, y haya tiempo suficiente para volver a expedirla, se le cobrará un cargo para la reemisión de la misma, de acuerdo con el importe establecido en su Tabla Consolidada de Recargos (dicho importe era de 40 euros).

El Juzgado de lo Mercantil núm. 1 de Barcelona consideró en 2010 esta cláusula como abusiva y una vez recurrida esta decisión, la sección $15^{\text {a }}$ de la Audiencia Provincial de la misma ciudad, en sentencia de 5 de octubre de 2011, dictaminó que no se le podía dar tal calificación (aunque uno de los Magistrados realiza un voto particular a favor de considerarla nula).

El Juzgado de lo Mercantil de Barcelona hacía hincapié en que la obligación de expedir el documento de transporte corresponde al transportista, aunque el artículo 3 del Convenio de Montreal no lo indique expresamente, así debía deducirse de dicho Convenio (arts. 3.2 y 3.3); del artículo 3 del Convenio de Varsovia de 1929; del artículo 92 LNA; de otros contratos de transporte; de la costumbre o incluso de la jurisprudencia [SAP de Málaga (Sección 6a) de 17 de diciembre de 2007] que afirma que "cualquier recargo por emisión en la contratación de billete de avión, por cualquier mecanismo, ya lo sea electrónico a través de internet, ya en forma directa, queda

\section{Transporte aéreo de personas}

215 
incardinado en el concepto de abusivo" pues no puede ser "el viajero consumidor quien asuma los gastos de documentación del contrato de transporte aéreo que por imperativo legal debe ser asumido por la compañía aérea, sin darle alternativa de aceptar o rechazar voluntariamente el recargo".

Como consecuencia, el Juzgado de lo Mercantil de Barcelona basándose en el artículo 82 del TRDCU entendió que como corresponde la obligación de emitir el documento de transporte al transportista, imponer mediante una cláusula esa obligación al pasajero, alterando con ello las obligaciones contractuales básicas, produce un desequilibrio entre las prestaciones, limita los derechos del consumidor, determina una falta de reciprocidad y resulta desproporcionada [art. 82.4 b), c) y d)]. Por ello, declaró abusiva la cláusula y condenó a la compañía a la devolución de los 40 euros al pasajero.

El Magistrado que realizó el voto particular de la Sentencia de la AP de Barcelona porque discrepaba del sentido de la resolución de la mayoría, no discutía que el pasajero no quede informado de la existencia de la obligación, pero que una cláusula sea conocida por el consumidor no evita que pueda ser considerada como abusiva. El Magistrado hace referencia tanto a la cláusula general del artículo 82 como al artículo 86, párrafo primero, que considera abusivas "las cláusulas que limiten o priven al consumidor y usuario de los derechos reconocidos por normas dispositivas o imperativas". Esto supone que es abusiva cualquier alteración de los derechos que las normas jurídicas conceden al consumidor. Entiende el Magistrado que, como afirmaba la mayoría, puede considerarse efectivamente que es la compañía la que emite el billete o la tarjeta de embarque, y es el pasajero el que debe limitarse a llevarla impresa al aeropuerto. Sin embargo, se le está imponiendo al pasajero la obligación de utilizar sus propios medios para obtener en papel (hoy en día también puede llevarse en el teléfono móvil) la tarjeta de embarque, con lo cual se le están atribuyendo unas cargas que en otros casos no asume.

Aunque el realizar los pasos necesarios a través de internet no sea muy complejo, sin duda no puede incentivarse el cumplimiento de esa obligación mediante la amenaza de una penalización de 40 euros. Si bien puede suponer unos efectos beneficiosos para la mayor parte de los pasajeros al permitir ahorrar costes de personal y de tiempo al poder prescindir de un mayor número de personal de tierra encargado de la emitir las tarjetas de embarque a todos los pasajeros, el transportista no puede limitarse a emitir la tarjeta de embarque sino que debe hacer entrega de la misma. Por ello concluye que la cláusula es contraria a la buena fe, al alterar las obligaciones legales sin más razón que aportar un beneficio al predisponente. Sí sería admisible que la compañía aérea hubiera previsto un descuento para el pasajero que no utilizara los medios de la compañía aérea para obtener la tarjeta de embarque, pero no en cambio que se le penalice por no llevar a cabo una actuación que no le corresponde.

De cualquier modo, pone de manifiesto el Magistrado, no puede saberse si la cantidad de 40 euros es un importe excesivo o no, puesto que probablemente la aerolínea no incurra en esos costes por la emisión de cada tarjeta de embarque. Y además, es desproporcionado que en muchos casos la cláusula de penalización (40 euros) supere el precio de la prestación principal (el transporte). Esto podría suponer la imposición al consumidor de una indemnización desproporcionadamente alta por no cumplir con sus obligaciones (art. 85.6 TRDCU). Por todo ello, el Magistrado discrepaba del pronunciamiento de la mayoría y considera abusiva la cláusula contractual analizada.

Por su parte la SAP de Barcelona, Sección 15a , de 5 de octubre de 2011 aunque aceptaba que del artículo 3 del Convenio de Montreal se deduce que se quiere hacer recaer la obligación de expedir el billete no sobre el pasajero, sino sobre el transportista, consideraba que cumple con su obligación de expedir el billete y la tarjeta de embarque siguiendo el "modus operand" que ha establecido la compañía y que el pasajero acepta, mediante el cual "la tarjeta de embarque no es 
confeccionada, expedida y entregada al pasajero en el momento del embarque en el mostrador de tierra de la compañía, sino [que] es puesta a disposición del pasajero en la página web de Ryanair con expresas instrucciones para que este la imprima y la lleve consigo al aeropuerto para ser mostrada en la puerta de embarque".

Sostenía la Audiencia que imponer al pasajero la obligación de imprimir la tarjeta de embarque no es un gravamen desproporcionado que implique un desequilibrio importante entre las prestaciones o limite de manera injustificada los derechos del consumidor o usuario, en definitiva que sea abusiva en el sentido del artículo 82 TRDCU. Según su perspectiva la cláusula de penalización estimula el cumplimiento de dicha obligación, y no se puede considerar un importe excesivo los 40 euros exigidos por la compañía. Concluye la Sentencia que "se trata, en definitiva, de un pacto amparado por la libertad contractual (art. 1255 CC), del que el pasajero es suficientemente informado y cuya aplicación (la cláusula penal) puede evitar con una mínima diligencia (entrar en la web de Ryanair, imprimir la tarjeta y no olvidar llevarla consigo al aeropuerto)".

5.2.2 Acción colectiva. Respecto a los pronunciamientos más recientes de los Tribunales sobre esta cláusula que trae causa en la demanda de la OCU, vamos a referirnos brevemente a las Sentencias del Juzgado de lo Mercantil $n^{\circ} 5$ de Madrid con fecha 30 de septiembre de 2013 y la Sentencia de la Audiencia Provincial de Madrid, sección 28, núm. 392/2017, de 26 de julio de 2017. En ambas sentencias parece haber un cambio de perspectiva al no discutirse tanto en sí la consideración de abusiva de la cláusula por trasladar lo que parece una obligación del transportista al consumidor y además cobrarle por no cumplirla, sino en lo excesivo del importe cargado como consecuencia.

Se alegaba por la OCU la nulidad por la imposición al consumidor de gastos de administración y tramitación que corresponden al empresario en los términos del artículo 89.3 TRLGDCU. Considera el Juzgado de lo Mercantil que es la compañía aérea la que emite el billete electrónico y la que remite la tarjeta de embarque. En cuanto a si la carga que asume el consumidor de imprimir la tarjeta de embarque se puede identificar con gastos que se deben imponer al profesional, si bien es cierto que se hace que el pasajero tenga que imprimir la tarjeta de embarque, no considera esta conducta como "gastos de tramitación y documentación", y aunque fuera así, no entiende acreditado que dichos gastos correspondan por ley al empresario, siendo un punto esencial para poder considerar la cláusula como abusiva por este motivo. Por otra parte, aunque la OCU alegaba que no todo el mundo dispone de correo y ordenador, pone de manifiesto el Juzgado que en la actualidad ya no hay billete en soporte papel, y que el consumidor tiene que acceder al billete por vía electrónica, por lo que no le puede ser ajeno el sistema de recepción de tarjeta de embarque utilizado por Ryanair.

La sentencia de primera instancia consideraba que examinando la cláusula a la luz del artículo 85.6 ("Las cláusulas que supongan la imposición de una indemnización desproporcionadamente alta, al consumidor y usuario que no cumpla sus obligaciones"), el importe de 40 euros previsto en la tabla de cargos en los anexos de los "Términos Generales y Condiciones de Transporte" como recargo por la reemisión de la tarjeta de embarque en el aeropuerto era abusivo.

El juez centraba su análisis en si el importe era desproporcionado o si se correspondía efectivamente con el coste que a la aerolínea le suponía la prestación del servicio. No consideraba determinante para reputar la cláusula como abusiva el que el importe de 40 euros por reemisión de la tarjeta de embarque pudiera ser superior al precio en sí del billete de avión. Pesaba sobre Ryanair la carga de la prueba de demostrar que el coste efectivo que la aerolínea asumía por poner a disposición de los pasajeros el servicio de reemisión de la tarjeta de embarque en los puntos de seguridad del aeropuerto o en la puerta de embarque justificaba el importe de los 40 euros. Como no quedo acreditado tal hecho en primera instancia el juez concluyó que el recargo de 40 resultaba desproporcionado y, por tanto, abusivo.

\section{Transporte aéreo de personas}


El juez de primera instancia se separó del criterio recogido en la Sentencia de la Sección 15 de la Audiencia Provincial de Barcelona en cuanto a la consideración por ésta del cargo de 40 euros como no excesivo, al entender que tal juicio no debía hacer desde una perspectiva abstracta, sino teniendo en cuenta los costes reales que para aerolínea suponía la prestación del servicio, para poder determinar la abusividad o no del recargo conforme al artículo 85.6 TRLGDCU [cláusula prevista en la letra e) del anexo de la Directiva 93/13].

La cláusula cuestionada fue considerada como cláusula penal, al quedar ligada al incumplimiento de la obligación asumida por el pasajero de imprimir su tarjeta de embarque y acudir con ella al aeropuerto. Como se ha visto, en primera instancia se considera válida en sí la previsión de la cláusula que impone un recargo por la reemisión de la tarjeta de embarque, lo que se considera abusivo por desproporcionado es el importe de 40 euros. La OCU no formula en sí impugnación contra la previsión de tal cláusula penal, sino por el importe. Por ello, la sentencia de la AP se centra también sólo en determinar si dicho importe supone una indemnización desproporcionadamente alta.

La SAP de Madrid coincide con la de primera instancia en cuanto a que no supone un factor determinante para examinar la nulidad de la cláusula que la información facilitada al consumidor sobre la existencia del cargo fuese adecuada, además de que le fuese "fácil" eludir tal cargo, e incluso que tal medida pueda cumplir un efecto disuasorio que supone un ahorro de costes para la aerolínea y posiblemente también para los usuarios en su conjunto al poder reducir la compañía la tarifa.

Considera la AP siguiendo la STS de 15 de abril de 2014, que para determinar la abusividad de la cláusula según el artículo 85.6 TRLGCU es necesario comparar la cantidad exigida en la cláusula con el valor de los daños y perjuicios efectivamente causado al predisponente. En los casos en los que como el analizado, responde a una acción colectiva de cesación, en la que hay que analizar magnitudes colectivas y globales y realizar cálculos teóricos sobre los gastos que supondría a Ryanair el que no se aplicase el recargo por reemisión e impresión de la tarjeta de embarque en sus mostradores del aeropuerto, la regla ha de modularse. Dicha carga de la prueba correspondería Ryanair, ya que sólo ella puede determinar el importe del cargo mencionado. Al no quedar acreditado el mismo, la SAP confirma la nulidad del importe de los 40 euros.

En estos años el importe del cargo por reemisión de la tarjeta de embarque ha ido fluctuando posiblemente en función de las distintas sentencias que se iban dictando sobre el asunto, pasando de los iniciales 40 euros, subiendo hasta 60, bajando hasta los 15 euros, para quedarse en el momento actual en 20 euros. Este parece un importe algo más razonable o acorde con los presumibles costes que le pueda suponer a la compañía la prestación de dicho servicio.

\section{Recapitulación final}

Se puede concluir que el transportista es libre de establecer las condiciones que estime convenientes en los contratos de pasaje y que el hecho de que una cláusula contractual se halle incardinada en un contrato de adhesión no la convierte en abusiva, sino que es necesario que por su contenido tenga tal carácter. No obstante, las cláusulas abusivas en los contratos de transporte aéreo de pasajeros son una realidad y afectan a los consumidores en un ámbito en el que se encuentran especialmente indefensos.

Una de las sentencias más recientes y que mayor número de cláusulas nulas declara ha sido la analizada SAP de Madrid de 26 de julio de 2017 que resuelve recurso contra la sentencia del Juzgado de lo Mercantil n ${ }^{\circ} 5$ de Madrid con fecha 30 de septiembre de 2013 en la que la OCU demandaba a Ryanair por el uso de dichas cláusulas.

Especialmente relevante parece la cláusula sobre el cargo de 40 euros por la reemisión de la tarjeta de embarque al pasajero, pues unos años antes ya la estudiaron 
los Tribunales de Barcelona ante el ejercicio de una acción individual. En primera instancia determinaron que se trataba de una cláusula abusiva centrándose en el discurso de que la emisión de la tarjeta de embarque era una obligación de la aerolínea que trasladaban al consumidor y que además el importe cobrado por la reemisión era muy elevado; y, en cambio, en el recurso interpuesto por Ryanair la AP de Barcelona consideró que no se trataba de una cláusula abusiva porque el transportista cumplía con su obligación mediante la emisión electrónica del billete y la tarjeta de embarque y que el importe de 40 euros tampoco era desproporcionado en la medida en que cumplía una función disuasoria del uso de este servicio de Ryanair, respondiendo a la necesidad de abaratar costes para la aerolínea al no tener que destinar tanto personal en tierra, lo cual beneficiaría al colectivo de los usuarios.

Sin embargo, parece más ajustada a Derecho la interpretación realizada por la SAP de Madrid (en línea con la sentencia del Juzgado de lo Mercantil de Madrid) pues ya no se cuestiona que la aerolínea cumple con su obligación de emisión de la tarjeta de embarque vía electrónica, por lo que la cláusula en sí no es nula, pero sí que se considera desproporcionado el importe de 40 euros al no responder al coste efectivo que supone para la aerolínea la reemisión de la misma.

Desde la óptica de la protección del consumidor es indiscutible que ni la publicidad de la cláusula ni el precio de la prestación principal pueden justificar una cláusula penal de esta índole por un importe tan desproporcionado. Sin embargo, en algunos casos parece que son las compañías low cost las más propensas a incluir cláusulas abusivas justificándolo en su necesidad de compensar sus bajos precios. En este sentido, cabe mencionar la nueva política de equipaje de mano de pago de Ryanair que empezó a aplicarse a partir del 1 de noviembre de 2018, que la OCU alega que es contraria al artículo 97 de la LNA (el cual dispone que "El transportista estará obligado a transportar de forma gratuita en cabina, como equipaje de mano, los objetos y bultos que el viajero lleve consigo"[...D, y que en Italia ha supuesto que l'Autorità Garante della Concorrenza e del Mercato en su Resolución de 20 de febrero de 2019 multe a la aerolínea con tres millones de euros por engañar al consumidor sobre el efectivo precio del billete por no incluir en la tarifa básica un elemento esencial en el transporte aéreo como es la maleta de mano grande.

\section{Bibliografía}

Botana, G. (2011), "Título I. Contratos con los consumidores y usuarios. Capítulo I. Disposiciones generales. Comentarios a los artículos 59, 62 y 63”, en Rebollo, M. and Izquierdo, M. (dir.), $L a$ Defensa de Los Consumidores y Usuarios, Iustel, Madrid, pp. 1035-1105.

Broseta, P.M. and Martínez, S.F. (2018), Manual de Derecho Mercantil, Vol. 2, Tecnos, Madrid.

Cano Ortega, C. (2013), "Cláusulas abusivas en el contrato de transporte aéreo: la exigencia de la impresión de la tarjeta de embarque”, en Jiménez, G. y Díaz, A. (dir.), Estudios de Derecho Del Comercio Internacional, Marcial Pons, Madrid, pp. 221-233.

Castellanos, R.E. (2011), “Artículo 67”, Comentarios a Las Normas de Protección de Los Consumidores, en Cámara, S. (dir.), Colex, Madrid, pp. 590-614.

Clemente, M.E. (2002), “La protección del consumidor en los contratos electrónicos”, en Orduña, J. (dir.), Contratación y Comercio Electrónico, Tirant lo blanch, Valencia, pp. 365-403.

García, P. and Lastres, J.L. (2003), Derecho Mercantil de Obligaciones. Parte General, Marcial Pons, Madrid.

Gómez Lozano, M. (2010), "Vuelos de bajo coste, agencias de viajes virtuales y derecho de la competencia", Revista de Derecho UNED, Vol. 7, pp. 599-615.

Guerrero, L.J. (2003), "Nuevas tendencias en la documentación del transporte aéreo de pasajeros: el billete electrónico", Revista de la Contratación Electrónica, Vol. 38, pp. 3-25.

Fernández, R.L. (2001), Elementos de Derecho Mercantil, Ed. Deusto, Bilbao.
Transporte aéreo de personas 
Fernández, D.I. (2002), “Algunas notas acerca de la contratación y el comercio electrónico”, en Orduña, J. (dir.), Contratación y Comercio Electrónico, Tirant lo blanch, Valencia, p. 245.

López Bonilla, J.M. and López Bonilla, L.M. (2008), "El billete electrónico en los canales de distribución turísticos", Boletín Económico de ICE, Vol. 2934, pp. 43-53.

Martín, O.J.M. (2013), “Cargo económico adicional por emisión del billete electrónico en el transporte aéreo", Revista de Derecho Del Transporte: Terrestre, Maritimo y Multimodal, Vol. 12, pp. 139-158.

Martínez, R.J. (2013), "Nulidad de ciertas cláusulas por abusivas en el transporte aéreo. Comentario a la SJMER núm. 8 de Barcelona, de 23 de Mayo de 2012", en Petit, M.V. (dir.), La Nueva Ordenación Del Mercado de Transporte, Marcial Pons, Madrid, pp. 617-628.

Miquel, G.M. (2011), “Artículo 82”, en Cámara, S. (dir.), Comentarios a Las Normas de Protección de Los Consumidores, Colex, Madrid, p. 710.

O’Callaghan, X. (1994), “Control y requisitos de las condiciones generales de los contratos, en protección de los consumidores”, en Nieto, U. (coord.), Seguridad Jurídica y Contratación Mercantil, Civitas, Madrid, pp. 197-216.

Otero, C.M.T. (2017), "Información incompleta en el proceso de venta de billetes de avión y nuevas tarifas abusivas de las compañías aéreas (comentario a la STJUE de 6 de julio de 2017, asunto C-290/16)", Revista de Derecho Del Transporte: Terrestre, Maritimo y Multimodal, Vol. 20, pp. 245-253.

Pazos, C.R. (2018), La Protección Del Consumidor en el Transporte Aéreo de Pasajeros, Bosch, Barcelona.

Pérez, G.R. (2014), "La intervención administrativa en el sector turístico español: la política turística", Revista Aragonesa de Administración Pública, Vols 43/44, pp. 396-413.

Pérez, G.R. (2017), "La regulación jurídico-administrativa de la intermediación turística en españa a la luz de la nueva directiva de viajes combinados: las agencias de viajes en andalucía”, Revista Aragonesa de Administración Pública, Vols 49/50, pp. 432-453.

Pérez, G.R. and Ceballos, M.M. (2009), "La configuración del derecho del turismo autonómico español en el ordenamiento jurídico administrativo-constitucional”, Revista Aragonesa de Administración Pública, Vol. 35, pp. 455-515.

Petit, L. and Guerrero, L. (2010), "Transporte aéreo (I). régimen jurídico. Contrato de transporte aéreo", en Martínez, F. (dir.), Manual de Derecho Del Transporte, Marcial Pons, Madrid, pp. 333-350.

Sánchez-Calero, F. and Sánchez-Calero, G.J. (2011), Instituciones de Derecho Mercantil, Vol. 2, AranzadiThomson Reuters, Cizur Menor (Navarra).

Vázquez, R.T. (2015), “Condiciones generales de la contratación en el transporte aéreo. Especial consideración a las cláusulas abusivas”, en Guerrero, M.J. (dir.), $L a$ Responsabilidad Del Transportista Aéreo y la Protección de Los Pasajeros, Marcial Pons, Madrid, pp. 299-332.

Zubiri, D. (2004), "El contrato de pasaje", en Bercovitz, A. (dir.), Contratos Mercantiles, ThomsonAranzadi, Cizur Menor (Navarra), pp. 1015-1045.

\section{Corresponding author}

Cristina Cano Ortega can be contacted at: cristinacano@ual.es

For instructions on how to order reprints of this article, please visit our website:

www.emeraldgrouppublishing.com/licensing/reprints.htm

Or contact us for further details: permissions@emeraldinsight.com 